\title{
Targeted lymphodepletion with a CD45-directed antibody radioconjugate as a novel conditioning regimen prior to adoptive cell therapy
}

\author{
Wojciech Dawicki ${ }^{1}$, Kevin J.H. Allen ${ }^{1}$, Ravendra Garg ${ }^{1}$, Eileen M. Geoghegan ${ }^{2}$, \\ Mark S. Berger ${ }^{2}$, Dale L. Ludwig' ${ }^{2}$ and Ekaterina Dadachova ${ }^{1}$ \\ ${ }^{1}$ College of Pharmacy and Nutrition, University of Saskatchewan, Saskatoon, SK, Canada \\ ${ }^{2}$ Actinium Pharmaceuticals, New York, NY, USA \\ Correspondence to: Dale L. Ludwig, email: dludwig@actiniumpharma.com \\ Keywords: anti-CD45 targeted lymphodepletion; radioimmunotherapy; adoptive cell therapy; 131lodine; 177Lutetium \\ Received: June 13, $2020 \quad$ Accepted: August 17, $2020 \quad$ Published: September 29, 2020
}

Copyright: $\odot 2020$ Dawicki et al. This is an open access article distributed under the terms of the Creative Commons Attribution License (CC BY 3.0), which permits unrestricted use, distribution, and reproduction in any medium, provided the original author and source are credited.

\section{ABSTRACT}

Chimeric antigen receptor (CAR) T cell therapies, and adoptive cell therapy (ACT) in general, represent one of the most promising anti-cancer strategies. Conditioning has been shown to improve the immune homeostatic environment to enable successful ACT or CAR-T engraftment and expansion in vivo following infusion, and represents potential point of intervention to decrease serious toxicities following CAR-T treatment. In contrast to relatively non-specific chemotherapy-derived lymphodepletion, targeted lymphodepletion with radioimmunotherapy (RIT) directed to CD45 may be a safer and more effective alternative to target and deplete immune cells. Here we describe the results of preclinical studies with an anti-mouse CD45 antibody 30F11, labeled with

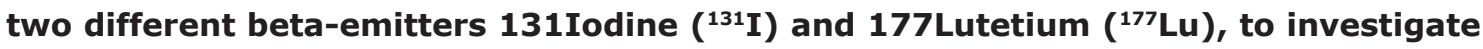
the effect of anti-CD45 RIT lymphodepletion on immune cell types and on tumor control in a model of adoptive cell therapy. Treatment of mice with $3.7 \mathrm{MBq}{ }^{131} \mathrm{I}-30 \mathrm{~F} 11$ or $1.48 \mathrm{MBq}{ }^{177} \mathrm{Lu}-30 \mathrm{~F} 11$ safely depleted immune cells such as spleen CD4+ and CD8+ $T$ cells, B and NK cells as well as Tregs in OT I tumor model while sparing RBC and platelets and enabled E. G7 tumor control. Our results support the application of CD45-targeted RIT lymphodepletion with a non-myeloablative dose of ${ }^{131}$ I-30F11 or ${ }^{177}$ Lu-30F11 antibody prior to adoptive cell therapy.

\section{INTRODUCTION}

Chimeric antigen receptor (CAR) $\mathrm{T}$ cell therapies, and adoptive cell therapy (ACT) in general, represent one of the most promising anti-cancer strategies [1]. To date, two autologous CAR-T cell therapies directed against CD19 have been approved for use in the treatment of B-cell lymphomas including relapsed or refractory acute lymphoblastic lymphoma (ALL) and diffuse large cell B-cell lymphoma (DLBCL) [2]. Initial response rates in these heavily pretreated patients have been extraordinary, in the range of $80 \%$, although durable responses have been considerably lower at $40-50 \%$ [2]. There are now nearly 1000 clinical trials involving CAR-T cells in the US (https://clinicaltrials.gov/), including expanding to new targets such as BCMA and CD123 in heme malignancies and various targets in solid tumors. Further, recombinant $\mathrm{T}$ cell receptor (TCR) engineered T cells, TCR-T that are directed against MHC-complexed peptides, are also being evaluated primarily in solid tumors [3].

It is unclear why some patients respond to treatment with adoptive cell therapies such as CAR-T, and others do not, though the tumor immune microenvironment is a likely contributor to variable effect of cell therapy in both hematologic and solid cancers. To this end, preclinical and clinical studies have shown that regulatory $\mathrm{T}$ cells (Tregs) can have an impact on the effect of ACT in mice and in patients with melanoma $[4,5]$. In these studies, depletion of Tregs, whether by specific depletion or via conditioning with external beam radiation, had a favorable impact on the anti-tumor response to ACT. Interestingly, these and other studies suggest that Treg depletion is more 
sustained following treatment with radiation as opposed to chemotherapy-induced conditioning [6], where a rapid rebound of Tregs was seen with chemotherapy conditioning resulting in poorer outcomes. Other cell types that contribute to an immunosuppressive tumor microenvironment that may negatively impact CAR-T efficacy include myeloid derived suppressor cells (MDSCs) and tumor-associated macrophages (TAMs) [7].

Another important area for improvement in CAR-T therapies involves the serious adverse events that have been reported, particularly with the drugs directed against CD19 such as tisagenlecleucel and axicabtagene ciloleucel. Cytokine release syndrome (CRS) and immune effector cell-associated neurotoxicity syndrome (ICANS) occur at very high rates following CD19 CAR-T administration, with CRS occurring in greater than $50 \%$ of patients and at least 10-30\% patients experiencing high grade ICANS [2]. Recent preclinical studies have shown that cytokine release leading to CRS or neurotoxicity is due to activated macrophages following recruitment to the site of CAR-T and tumor cells. Mouse study results $[8,9]$ documented that macrophages secrete IL-1 or IL-6 following recruitment and activation by CAR-T cells at the tumor site.

Conditioning has been shown to improve the immune homeostatic environment to enable successful ACT or CAR-T engraftment and expansion in vivo following infusion, and represents a potential point of intervention to decrease serious toxicities following CAR-T treatment. Most CAR-T programs exploit the use of the combination of fludarabine and cyclophosphamide (flu/cy) as a lymphodepletive conditioning regimen prior to CAR-T. These drugs are often administered 2-7 days (2-5 day course of therapy) prior to ACT infusion. However, the commonly used flu/cy regimen is a nonspecific and cytotoxic treatment that some patients may not be able to tolerate and may not offer tumor control. Additionally, flu/cy has been correlated with toxicities such as prolonged cytopenias and cytokine release syndrome (CRS) following CAR-T administration [10].

In contrast to relatively non-specific chemotherapyderived lymphodepletion, targeted lymphodepletion with radioimmunotherapy (RIT) directed to CD45 may be a safer and more effective alternative to target and deplete immune cells. The CD45 antigen is found on all nucleated immune cells, with increased expression on mature lymphoid and myeloid lineages, leading to preferential depletion of mature immune cells compared to progenitor hematopoietic cells [11]. Importantly, immunomodulatory cells such as Tregs and MDSC express CD45 and are targets of lymphodepletion with a CD45-targeting antibody-radionuclide conjugate (ARC), potentially resulting in better engraftment, activation and persistence of the exogenously added CAR-T cells in patients. In addition, macrophages, implicated in CRS, are also sensitive to targeting with a CD45 ARC, and their transient reduction may result in mitigation of CRS risk. In addition, most hematologic malignancies such as leukemia and lymphoma abundantly overexpress CD45, at levels of 200 to 400,000 antigens per cell. Targeted lymphodepletion with a CD45 ARC is anticipated to result in a reduction in tumor burden, which may result in an improvement in overall response to the CAR-T therapy.

Anti-CD45 RIT with 131Iodine ( $\left.{ }^{131} \mathrm{I}\right)$-apamistamab (Iomab-B), is in a Phase III clinical trial as a myeloablative targeted conditioning regimen prior to allogeneic stem cell transplant in patients with active relapsed/refractory acute myeloid leukemia (AML). Results from patients following dosimetry testing have shown that low nonmyeloablative doses of ${ }^{131} \mathrm{I}$-apamistamab were able to safely induce transient lymphodepletion [12]. This data allowed us to hypothesize that low dose anti-CD45 RIT could be used as a targeted modality to effectively lymphodeplete prior to ACT. Here we describe the results of preclinical studies with an anti-mouse CD45 antibody 30F11, labeled with two different beta-emitters - ${ }^{131} \mathrm{I}$ and 177Lutetium $\left({ }^{177} \mathrm{Lu}\right)$, to investigate the effect of anti-CD45 RIT lymphodepletion on immune cell types and on tumor control in a model of adoptive cell therapy. Our results support CD45 targeted RIT lymphodepletion prior to adoptive cell therapy using a non-myeloablative dose of ${ }^{131} \mathrm{I}-30 \mathrm{~F} 11$ or ${ }^{177} \mathrm{Lu}-30 \mathrm{~F} 11$ antibody.

\section{RESULTS}

\section{${ }^{131}$ I-30F11 treatment transiently depleted CD45- expressing immune cell subsets in healthy mice}

microSPECT/CT imaging of mice administered CD45-targeting antibody 30F11 radiolabeled with ${ }^{111}$ In $\left({ }^{111}\right.$ In radiolabel was used in these experiments as imaging surrogate for therapeutic radionuclides ${ }^{131} \mathrm{I}$ and ${ }^{177} \mathrm{Lu}$ ) showed that the antibody homed to immune system organs such as lymph nodes, spleen, and bone marrow as well as liver (Figure 1A). The imaging data was confirmed by the pharmacokinetics data which also demonstrated fast clearance of the antibody from the blood and kidneys, and low uptake in the pancreas and gonads (Figure 1B). Dose finding studies using 1.85$7.4 \mathrm{MBq}{ }^{131} \mathrm{I}-30 \mathrm{~F} 11$ antibody were performed next to determine the appropriate dose of ${ }^{131}$ I needed to define a non-myeloablative dose to safely lymphodeplete. Figure $2 \mathrm{~A}$ shows that $3.7 \mathrm{MBq}$ dose of ${ }^{131} \mathrm{I}-30 \mathrm{~F} 11$ transiently depleted lymphocytes, splenocytes, and myeloid derived cells (MDSC) but preserved bone marrow cells, platelets, and red blood cells. Experiments in which variable amounts of 30F11 were radiolabeled with $3.7 \mathrm{MBq}{ }^{131} \mathrm{I}$ revealed no effect of the antibody amount on the efficacy of lymphodepletion (Figure 2B). Based on these results, $20 \mu \mathrm{g}$ of antibody was labeled with $3.7 \mathrm{MBq}{ }^{131} \mathrm{I}$ for targeted lymphodepletion in the follow-up experiments. Importantly, the detailed analyses of the depleted cells 
subpopulations showed that ${ }^{131} \mathrm{I}-30 \mathrm{~F} 11$ was able to deplete subsets such as spleen NK and B cells, neutrophils and spleen Tregs at a dose that did not impact bone marrow hematopoietic stem cells (HSCs) (Figure 3).

\section{${ }^{131}$ I-30F11 treatment safely depletes immune cells in OT I tumor model and enables tumor control}

Following E.G7 tumor engraftment, mice were conditioned with $3.7 \mathrm{MBq}{ }^{131} \mathrm{I}-30 \mathrm{~F} 11$ and received $10^{6}$ OT I CD8 CD45.2 OVA reactive T cells on day 4. Figure 4A shows that targeted lymphodepletion with ${ }^{131} \mathrm{I}-30 \mathrm{~F} 11$ antibody enabled engraftment and persistence of adoptively transferred CD45.2 OT I CD8+ T cells in the spleen 17 days post injection. Similar to conditioning in non-tumor bearing mice, ${ }^{131} \mathrm{I}-30 \mathrm{~F} 11$ lymphodepletion mediated decreases in multiple lymphoid cell subsets such as spleen CD4+, CD8+, B and NK cells as well as
Tregs. (Figure 4B). Importantly, while ${ }^{131} \mathrm{I}-30 \mathrm{~F} 11$ mediated targeted conditioning did not affect the tumor growth - the combination of ${ }^{131} \mathrm{I}-30 \mathrm{~F} 11$ mediated targeted conditioning and adoptively transferred OT I T cells enabled control of E.G7 tumor growth (Figure 4C). In the control group which received no conditioning or $\mathrm{T}$ cells and in ${ }^{131} \mathrm{I}-30 \mathrm{~F} 11$ alone groups, $0 \%$ of mice achieved complete response $(\mathrm{CR})$, while in the treated group which received immunodepletion followed by OT I cells, $50 \%$ of mice $(2 / 4)$ achieved CR $(p=0.02)$.

\section{${ }^{131} \mathrm{I}-30 \mathrm{~F} 11$ and ${ }^{177} \mathrm{Lu}-30 \mathrm{~F} 11$ treatment produced comparable effects on immune cells and tumor growth}

Pilot treatment of non-tumor bearing C57B/6 mice with 0.74 or $1.48 \mathrm{MBq}{ }^{177} \mathrm{Lu}-30 \mathrm{~F} 11$ antibody revealed that $1.48 \mathrm{MBq}{ }^{177} \mathrm{Lu}-30 \mathrm{~F} 11$ was effective in transiently
A

$$
1 \mathrm{~h} \quad 24 \mathrm{~h}
$$
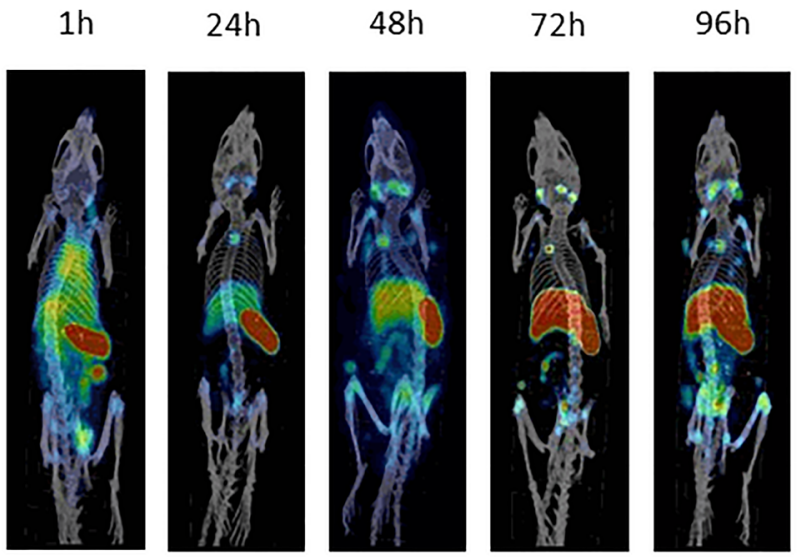

6 days

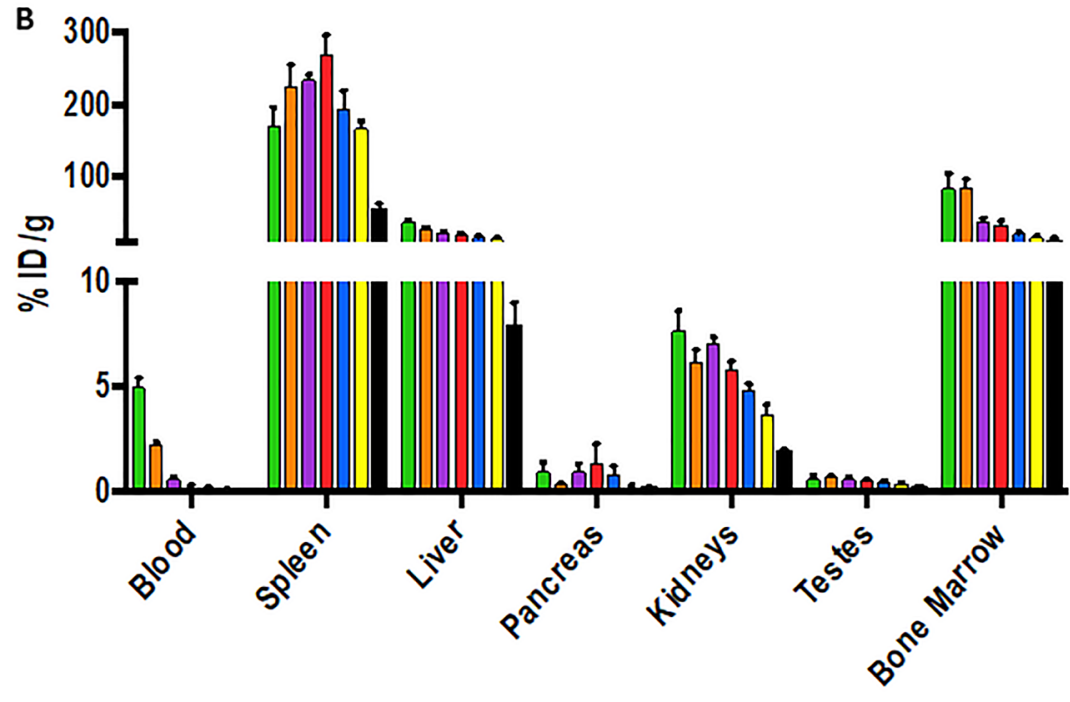

$\square 1 h$

$24 h$

$48 \mathrm{~h}$

$72 h$

$96 h$

$240 \mathrm{~h}$

Figure 1: ${ }^{111}$ In-30F11 anti-CD45 antibody homes to immune organs. (A) C57B1/6 mice were injected intraperitoneally (i.p.) with $60 \mu \mathrm{g}{ }^{111} \mathrm{In}-30 \mathrm{~F} 11$ antibody with a specific activity of $0.185 \mathrm{MBq} / \mu \mathrm{g}$ and antibody distribution was monitored by microSPECT/CT at $1,24,48,72,96$ hours timepoints and then again at 6 days after antibody administration. 30F11 antibody homed to immune organs: lymph nodes, spleen, and bone marrow, it also homed to the liver. (B) pharmacokinetics of ${ }^{111}$ In-labeled 30F11 in male $\mathrm{C} 57 \mathrm{Bl} / 6 \mathrm{mice}$. 
depleting various immune populations in the spleen including Tregs (Figure 5). Subsequently, we performed side by side comparison of lymphodepletion in non-tumor bearing C57B/6 mice with either 0.74 or $1.48 \mathrm{MBq}{ }^{177} \mathrm{Lu}-$ $30 \mathrm{~F} 11$ or 1.85 or $3.7 \mathrm{MBq}^{131} \mathrm{I}-30 \mathrm{~F} 11$. Both radiolabeled molecules were similarly effective in transiently lymphodepleting various immune cell populations without affecting bone marrow cells, red blood cells, or platelets (Figure 6). The experiment interrogating the ability of ${ }^{177} \mathrm{Lu}$ - and ${ }^{131} \mathrm{I}-30 \mathrm{~F} 11$ mediated targeted conditioning prior to adoptively transferred OT I T cells to control E.G7 tumor growth showed comparable effect of both agents on the tumor size and overall survival with $20 \%$ better tumor control and higher overall survival in ${ }^{131} \mathrm{I}-30 \mathrm{~F} 11$ treated group $(p=0.03)$ (Figure 7).

\section{DISCUSSION}

Prior to a patient receiving a dose of an adoptive cell transfer such as engineered autologous or allogeneic CAR-T cells, it is common to perform a lymphodepletion step often using high dose chemotherapy $[2,6]$. This process is considered important to create sufficient space in the immune microenvironment, e.g., bone marrow, to allow the transferred cells to engraft. Further, lymphodepletion appears to elicit a favorable cytokine profile for establishment and proliferation of the adoptively transferred lymphocytes [4]. In this study we demonstrate the feasibility and utility of radioimmunotherapy (RIT) using low non-myeloablative doses of ${ }^{131}$ I-radiolabeled anti-CD45 30F11 antibody
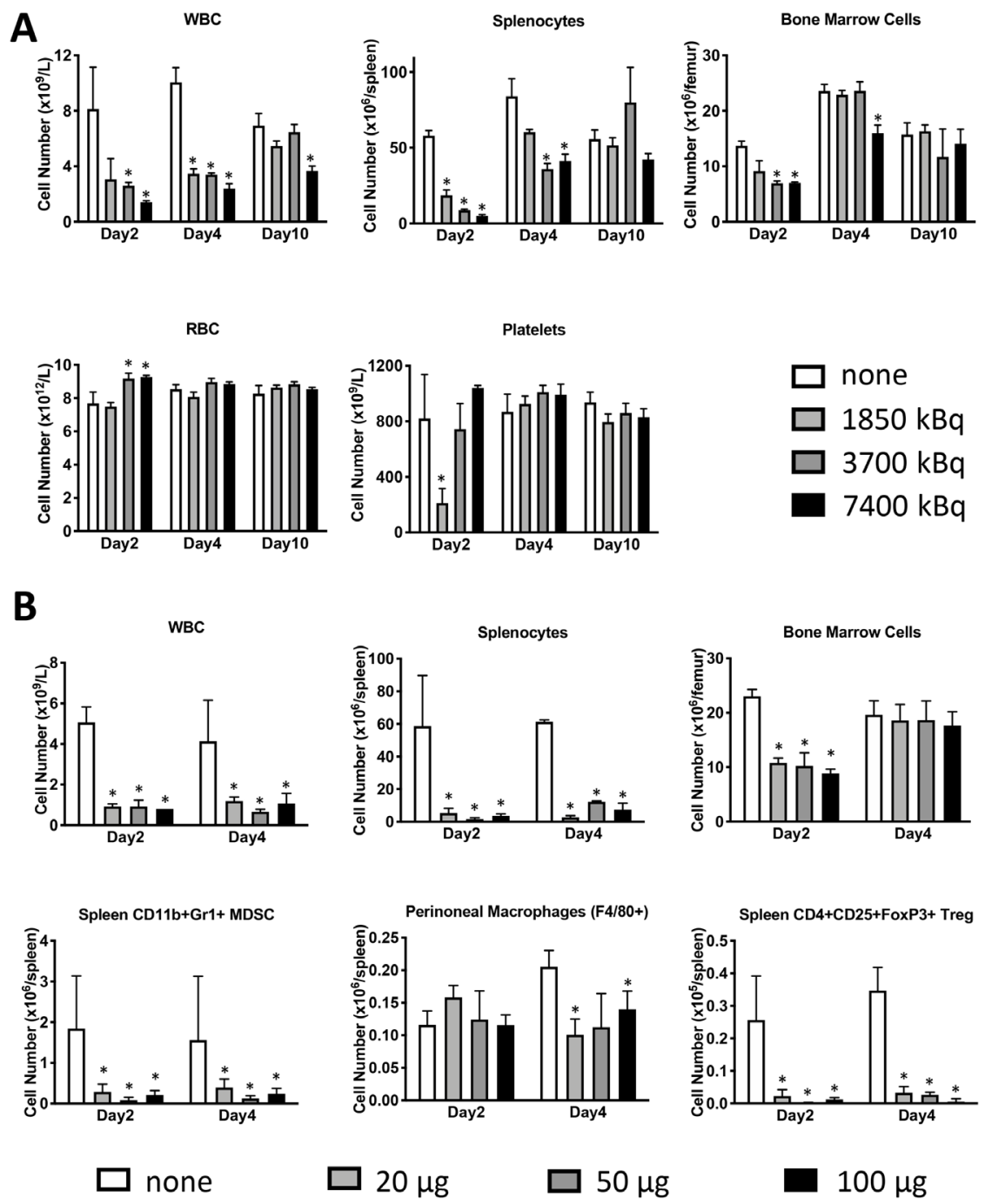

Figure 2: Lymphodepletion with ${ }^{131}$ I-labeled anti-CD45 $30 \mathrm{~F} 11$ antibody preserves bone marrow cells, platelets, and red blood cells but depletes splenocytes, Tregs and MDSC. (A) Dose finding studies were performed to determine the appropriate dose of ${ }^{131}$ I needed to define a non-myeloablative dose to safely lymphodeplete. Female C57B1/6 mice were injected i.p. with $20 \mu \mathrm{g} 30 \mathrm{~F} 11$ labeled with 1.85-7.4 MBq ${ }^{131}$ I to determine the most effective and safe radioactivity dose required for transient lymphodepletion. Mice were euthanized at varying time points (2-21 days) and various immune cell subsets were quantified using flow cytometry and (B) To determine the appropriate amount of antibody for labeling - varying amounts of 30F11 antibody were administered to a mouse in $20-100 \mu \mathrm{g}$ range, but with a constant activity of $3.7 \mathrm{MBq}$. Asterisks signify $P$ values $<0.05$. 
to effectively lymphodeplete in a targeted manner in experimental models prior to administration of adoptive cell therapy. Significantly, targeted conditioning with pan-CD45 RIT, which selectively targets all nucleated immune cells, depletes not only lymphocytes, but also macrophages, as well as immune suppressive regulatory $\mathrm{T}$ cells and myeloid-derived suppressor cells in the immune microenvironment. It can potentially also exert a direct anti-tumor effect on CD45+ hematopoietic cancers.

Subsequently, we investigated use of an alternate payload selection, specifically ${ }^{177} \mathrm{Lu}$, for mediating lymphodepletion in mouse models. Both ${ }^{131} \mathrm{I}$ and ${ }^{177} \mathrm{Lu}$ are beta emitters with physical half lives of 8 and 6.6 days, respectively, and maximum beta energies of 0.6 and $0.5 \mathrm{MeV}$, respectively. The principle difference lies in the chemistry of these radionuclides, with ${ }^{131} \mathrm{I}$ being a halogen and ${ }^{177} \mathrm{Lu}$ - a trivalent radiometal. ${ }^{177} \mathrm{Lu}$-labeled somatostatin receptor targeting peptide (Lutathera) has been approved for treatment of neuroendocrine tumors [13], and a ${ }^{177} \mathrm{Lu}$-labeled small molecule binding to PSMA is currently in advanced stage clinical trials for treatment of metastatic prostate cancer [14]. We have selected ${ }^{177} \mathrm{Lu}$ over another beta-emitting radiometal ${ }^{90} \mathrm{Y}$ as it has been shown in long term follow up studies that patients treated with ${ }^{177} \mathrm{Lu}$-peptide therapy survive significantly longer than those treated with ${ }^{90} \mathrm{Y}$-peptide therapy due to more side effects from ${ }^{90} \mathrm{Y}$ [15] which is a high energy beta emitter while ${ }^{177} \mathrm{Lu}$ is a low energy beta emitter. We determined that $1.48 \mathrm{MBq}{ }^{177} \mathrm{Lu}-30 \mathrm{~F} 11$ could effectively deplete various immune cell subsets in mice but spare bone marrow cells, red blood cells, and platelets. In a model of adoptive cell therapy using CD45.1 OT1 mice bearing E.G7-OVA tumors, mice that received either ${ }^{131} \mathrm{I}-30 \mathrm{~F} 11$ or ${ }^{177} \mathrm{Lu}-30 \mathrm{~F} 11$ RIT-mediated lymphodepletion demonstrated enhanced tumor control over mice that did not receive lymphodepletion. Interestingly, lymphodepletion with ${ }^{131}$ I-30F11 resulted in somewhat greater tumor control than with ${ }^{177}$ Lu-30F11 (Figure 7) which might be explained by the residualizing nature of ${ }^{177} \mathrm{Lu}$ which by persisting in the tumors due its residualization, can potentially kill some of the incoming adoptive $\mathrm{T}$ cells.

In conclusion, our data supports CD45 targeted RIT lymphodepletion with a non-myeloablative dose of ${ }^{131} \mathrm{I}-30 \mathrm{~F} 11$ or ${ }^{177} \mathrm{Lu}-30 \mathrm{~F} 11$ prior to adoptive cell therapy.

\section{MATERIALS AND METHODS}

\section{Antibodies and radiolabeling}

The anti-mouse pan-CD45 binding antibody 30F11 (ThermoFisher Scientific, Catalog \# 14-0451-82) was used in all experiments as a surrogate for pan-human CD45 ${ }^{131} \mathrm{I}$-apamistamab (Iomab-ACT) to perform targeted lymphodepletion in mice. Radiolabeling of 30F11 antibody with ${ }^{131} \mathrm{I}$ was carried out by adding $111 \mathrm{MBq} \mathrm{Na}{ }^{131} \mathrm{I}$ to 15 $\mu \mathrm{L}$ PBS followed by $100 \mu \mathrm{g} 30 \mathrm{~F} 11$ antibody $(1,111 \mathrm{MBq} /$ $\mathrm{mg})$ in a microcentrifuge tube. Chloramine- $\mathrm{T}(0.2 \mu \mathrm{L}, 10$ $\mathrm{mg} / \mathrm{mL}$ concentration) was added and the solution was shaken at RT for 5 minutes. Sodium thiosulfate $(22.8 \mu \mathrm{L}$, $0.3 \mathrm{mg} / \mathrm{mL}$ concentration) was added followed by $1 \mu \mathrm{L}$ Sodium Iodide solution $(10 \% \mathrm{w} / \mathrm{v})$ and $7.5 \mu \mathrm{L}$ of Ascorbic acid (500 $\mathrm{mg} / \mathrm{mL}$ concentration). The antibody was then
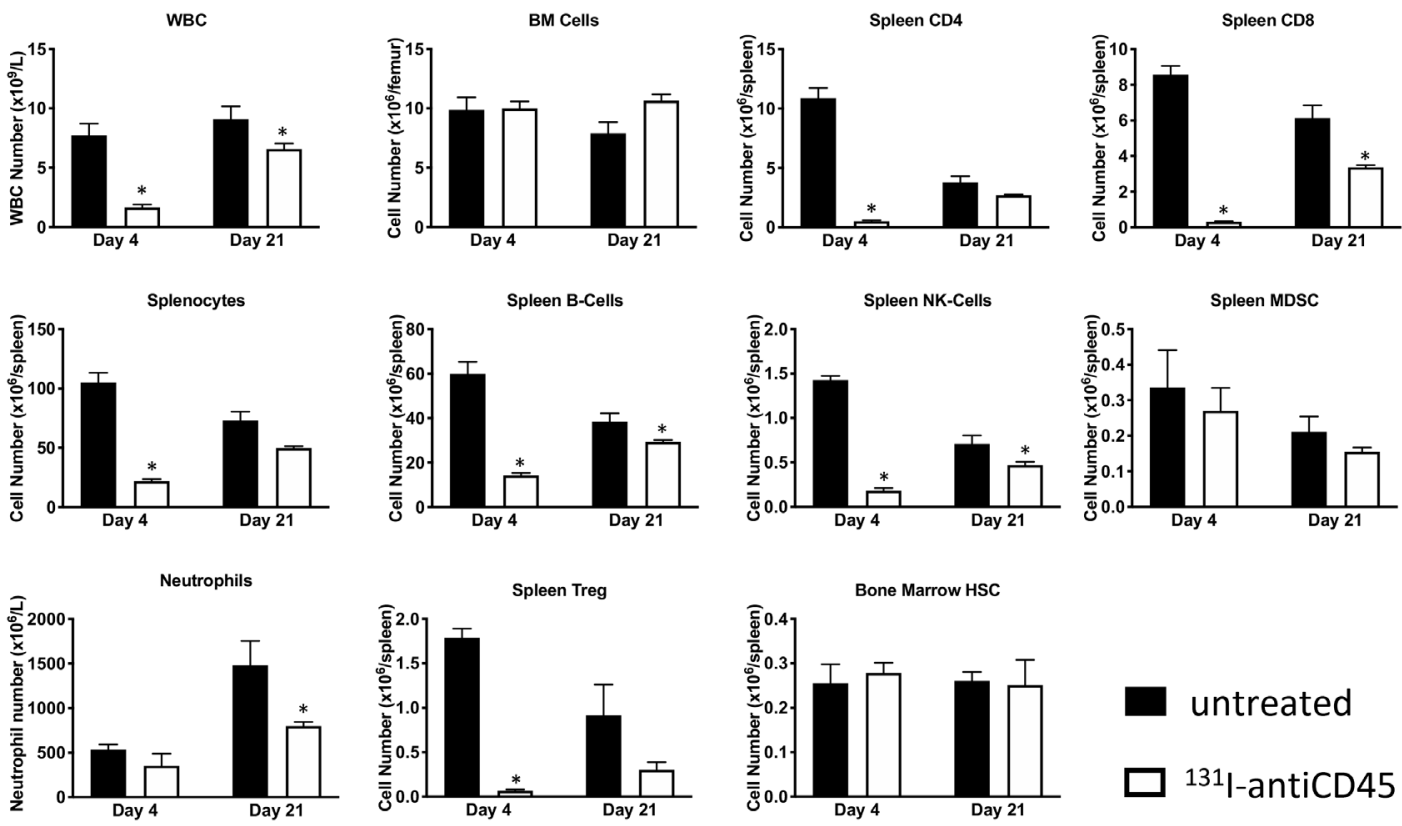

Figure 3: Treatment with ${ }^{131}$ I-labeled anti-CD45 30F11 antibody transiently depletes CD45-expressing immune cell subsets. Treatment of non-tumor bearing C57B/6 mice with $3.7 \mathrm{MBq}{ }^{131} \mathrm{I}-30 \mathrm{~F} 11$ antibody was effective in transiently lymphodepleting various lymphocyte populations such as WBC, CD4+ cells, CD8+ cells, splenocytes, B cells, MDSC, NK cells, neutrophils and Tregs at a dose that does not impact bone marrow HSCs. Asterisks signify $P$ values $<0.05$. 
purified using spin filtration via an Amicon Ultra $0.5 \mathrm{~mL}$ centrifugal filter (30 K MW cut off, Fisher, Hampton, NH, USA). Radiochemical purity was then checked via instant thin layer chromatography (iTLC) and was greater than $99 \%$. For radiolabeling with ${ }^{177} \mathrm{Lu}$ and ${ }^{111}$ In (imaging surrogate of $\left.{ }^{177} \mathrm{Lu}\right) 30 \mathrm{~F} 11$ antibody was conjugated to bifunctional chelating agent DOTA (Macrocyclics, USA) at a ratio 20:1 DOTA: $\mathrm{Ab}$ and then radiolabeled with ${ }^{177} \mathrm{Lu}$ or ${ }^{111} \mathrm{In}$ with the specific activity of $0.185 \mathrm{MBq} /$ $\mu \mathrm{g}$ antibody as in $[16,17]$. Immunoreactivity of the
A

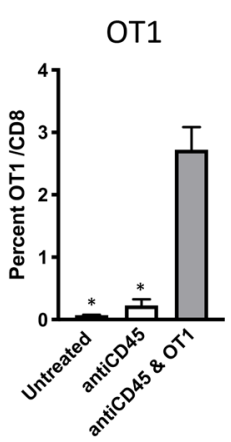

OT1

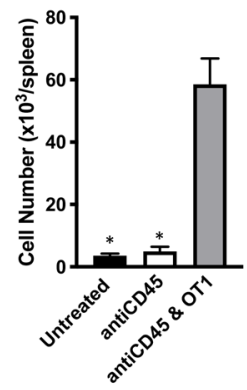

C Untreated

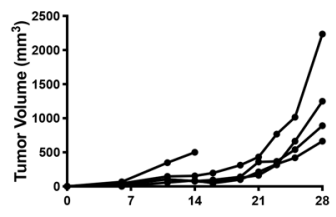

B
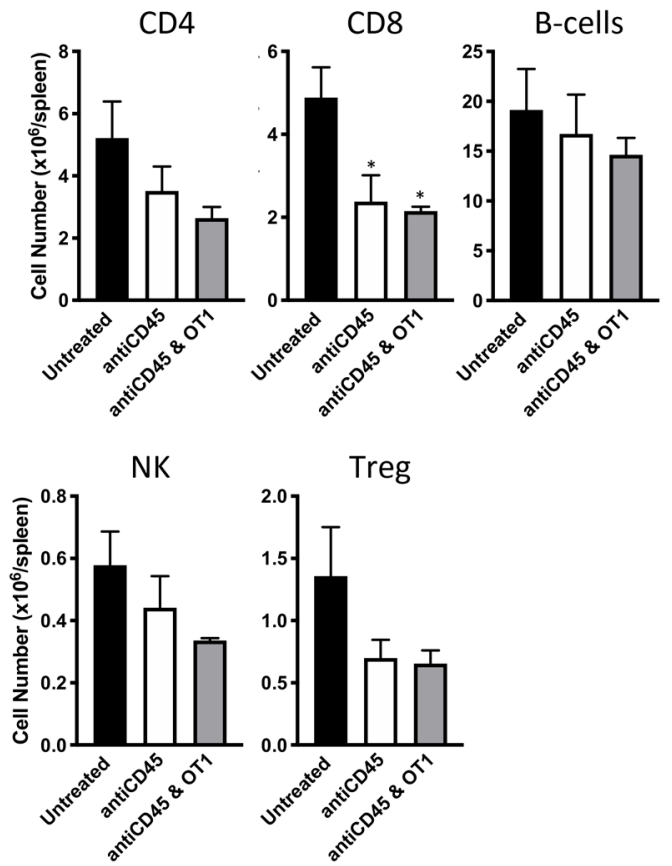

${ }^{131} \mid$-antiCD45
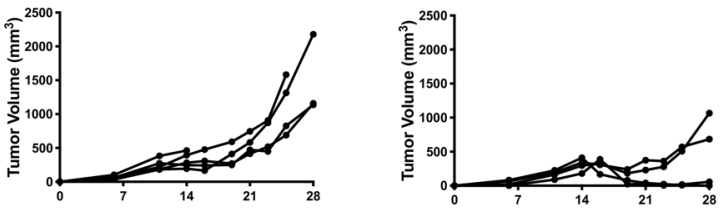

Mean Tumor Vol.
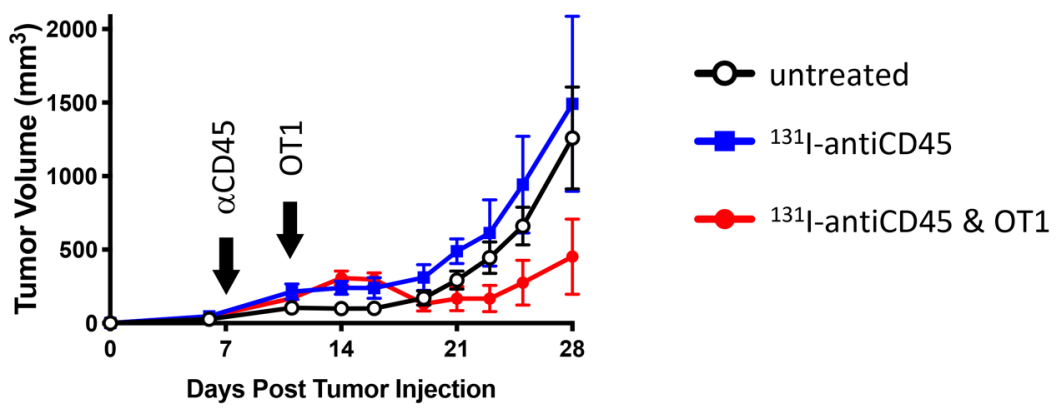

Figure 4: Lymphodepletion with ${ }^{131}$ I-labeled anti-CD45 $30 \mathrm{~F} 11$ antibody enables tumor control in OT I adoptive cell therapy model. Following E.G7 tumor engraftment, mice were conditioned with $3.7 \mathrm{MBq}{ }^{131} \mathrm{I}-30 \mathrm{~F} 11$; or received $3.7 \mathrm{MBq}{ }^{131} \mathrm{I}-30 \mathrm{~F} 11$ followed by $10^{6}$ OT I CD8 CD45.2 OVA reactive T cells on day 4. Control mice received no conditioning or T cells. (A) Targeted lymphodepletion with ${ }^{131} \mathrm{I}-30 \mathrm{~F} 11$ antibody enables engraftment and persistence of adoptively transferred CD45.2 OTI CD8+ T cells in the spleen 17 days post injection. (B) Similar to conditioning in non-tumor bearing mice, lymphodepletion with ${ }^{131}$ I-30F 11 mediated decreases in multiple lymphoid cell subsets. (C) ${ }^{131} \mathrm{I}-30 \mathrm{~F} 11$ mediated targeted conditioning and adoptively transferred OT I T cells enabled control of E.G7 tumor growth. In $3.7 \mathrm{MBq}{ }^{131} \mathrm{I}-30 \mathrm{~F} 11$ plus OT I T cells group 2/4 mice achieved CR; in $3.7 \mathrm{MBq}{ }^{131} \mathrm{I}-30 \mathrm{~F} 11$ alone group 0/5 mice achieved CR; in untreated control group, $0 / 5$ mice achieved CR. $N=4-5$ per group. Asterisks signify $P$ values $<0.05$. 
radiolabeled 30F11 antibody was evaluated by measuring binding to E.G7-OVA cells at concentrations ranging from $0.5 \mathrm{ng} / \mathrm{mL}$ to $10 \mu \mathrm{g} / \mathrm{mL}$ and detecting the bound antibody with flow cytometry and anti-rat $\operatorname{IgG} 2 \mathrm{~b}^{\mathrm{PE}}$. The $\mathrm{EC}_{50}$ for naked and modified 30F11 was $394 \mathrm{ng} / \mathrm{mL}$ and $393 \mathrm{ng} /$ $\mathrm{mL}$, respectively (Supplementary Figure 1).

\section{MicroSPECT/CT imaging of C57Bl/6 mice with ${ }^{111}$ In-labeled 30F11 antibody}

Female 5 weeks old C57Bl/6 mice were injected intraperitoneally (i.p.) with $60 \mu \mathrm{g}{ }^{111} \mathrm{In}-30 \mathrm{~F} 11$ antibody with a specific activity of $0.185 \mathrm{MBq} / \mu \mathrm{g}$ and antibody distribution was monitored by microSPECT/CT at 1, 24, 48, 72, 96 hours timepoints and then again at 6 days after antibody administration. A MILabs VECTor ${ }^{4}$ (Netherlands) microSPECT/CT scanner was used to collect images. PMOD (version 3.9, PMOD Technologies, Inc, Zürich, Switzerland) was used for comprehensive image analysis. An Extra Ultra High Sensitivity Mouse (XUHS-M) collimator for 20-350 $\mathrm{keV}$ range was used to collect SPECT data using spiral trajectories. MILABS reconstruction software was used to reconstruct SPECT images using both ${ }^{111}$ In gamma emissions (245 keV and $171 \mathrm{keV}$ ) on a $0.4 \mathrm{~mm}$ voxel grid. For visual representation of accumulation, MIP images were utilized.
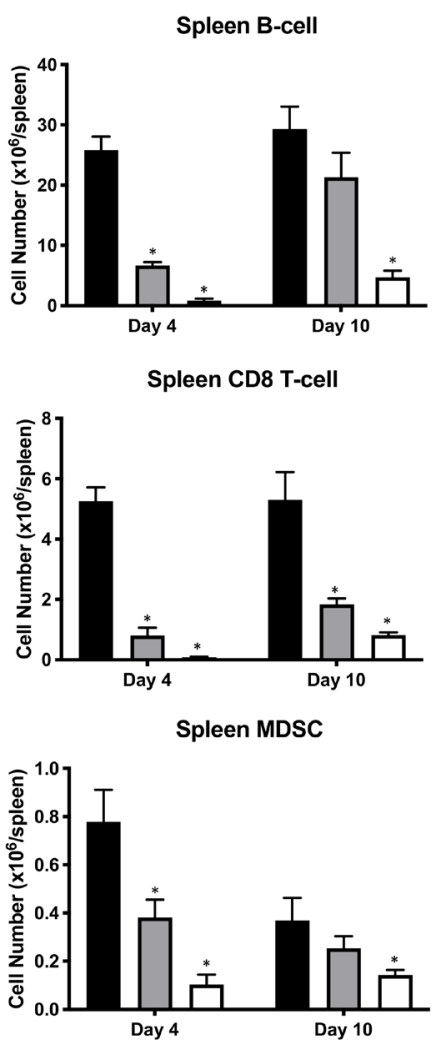

untreated

\section{Biodistribution of 30F11 antibody}

To determine the pharmacokinetics of $30 \mathrm{~F} 11$ antibody in immunocompetent mice, a biodistribution was carried out with ${ }^{111}$ In-labeled 30F11. Immediately after labelling male $\mathrm{C} 57 \mathrm{bl} / 6$ mice were injected i.v. with 1.11 $\mathrm{MBq}(30 \mu \mathrm{g}){ }^{111} \mathrm{In}-30 \mathrm{~F} 11$. Five mice were euthanized at 1 , 4, 24, 48, 72, 96 and 240 hours post injection, the organs were collected into pre-weighted tubes, and activity was assessed with a 2470 Wizard2 Gamma counter (Perkin Elmer, MA, USA). A standard that contained $10 \%$ of the injected dose was also read to perform decay correction. Percent injected dose per gram $(\% \mathrm{ID} / \mathrm{g})$ was determined using the equation:

$\% \mathrm{ID} / \mathrm{g}=\left((\right.$ sample $\mathrm{CPM}) /\left(\right.$ organ weight ${ }^{*}$ (standard $\left.\mathrm{CPM}^{*} 10\right)^{*}$ radiolabeling yield $\left.)\right) \times 100 \%$, where $\mathrm{CPM}$ are counts per minute.

\section{Lymphodepletion studies with ${ }^{131}$ I-30F11}

In the first series of experiments, female 5 weeks old $\mathrm{C} 57 \mathrm{Bl} / 6$ mice were injected i.p. with $20 \mu \mathrm{g}$ of ${ }^{131} \mathrm{I}-30 \mathrm{~F} 11$ labeled with $1.85-7.4 \mathrm{MBq}$ to determine the most effective and safe radioactivity dose required for transient lymphodepletion. Mice were euthanized at

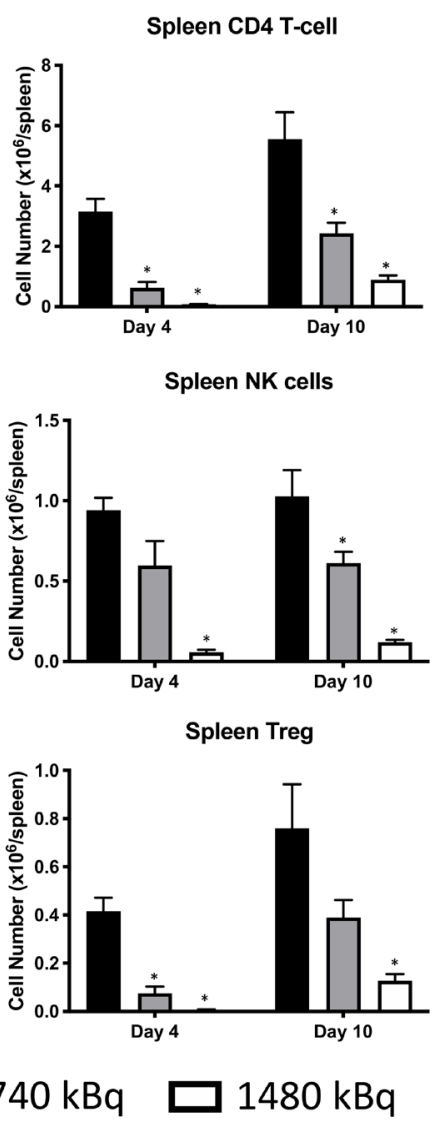

Figure 5: Treatment of non-tumor bearing C57B/6 mice with $1.48 \mathrm{MBq}{ }^{177} \mathrm{Lu}-30 \mathrm{~F} 11$ antibody was effective in transiently depleting various immune populations in the spleen such as CD4+ T cells, CD8+ T cells, B cells, MDSC, NK cells and Tregs. Asterisks signify $P$ values $<0.05$. 
varying time points (2-21 days) and various immune cell subsets were quantified using flow cytometry as described below. The goal of the second series of experiments was to determine the optimal amount of antibody to be used for lymphodepletion. This was accomplished by varying the amount of $30 \mathrm{~F} 11$ antibody administered to a mouse in $20-100 \mu \mathrm{g}$ range, but with a constant specific activity of 3.7 MBq.

\section{Flow cytometry}

Single cell suspensions were made by passing spleens through a $70 \mu \mathrm{m}$ cell strainer, washed three times with FACS buffer (0.01 M azide, 2\% FBS, PBS), incubated with blocking antibody for $10 \mathrm{~min}$ at $4{ }^{\circ} \mathrm{C}$, then labeled with surface marker-specific fluorochrome-labeled antibodies (Supplementary Table 1) for an additional 20 min at $4^{\circ} \mathrm{C}$ and unbound $\mathrm{Ab}$ was washed away with FACS buffer. Cells that were probed for intracellular markers were permeabilized (Fix/Perm Buffer; ThermoFisher Scientific, Waltham, MA, USA) for $30 \mathrm{~min}$, washed again with Perm buffer, incubated with blocking antibody in the same buffer for $10 \mathrm{~min}$, and then labeled with marker-specific or isotype control fluorochrome-labeled antibodies for an additional $20 \mathrm{~min}$. Stained cells were washed twice with Perm buffer and once with FACS buffer, and analyzed on a CytoFLEX flow cytometer (Beckman Coulter, Mississauga, ON). The data was processed using FlowJo software (Tree Star Inc., Ashland, OR). Supplementary Figure 2 shows gating scheme for the identifications of various immune cells.

\section{Lymphodepletion and tumor control studies with ${ }^{131} \mathrm{I}-30 \mathrm{~F} 11$ in OT I mouse model}

Three groups of female 5 weeks old C57Bl/6 CD45.1 mice, five animals per group, were injected subcutaneously with OVA expressing CD45+ E. G7-

\section{A}
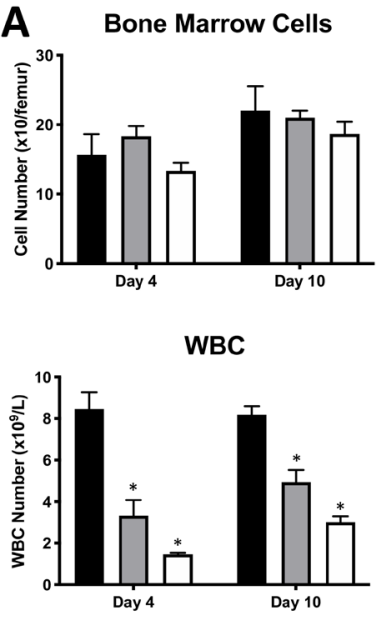

\section{B}
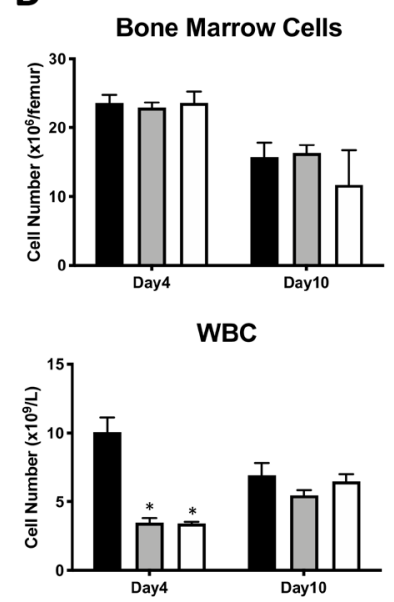

RBC

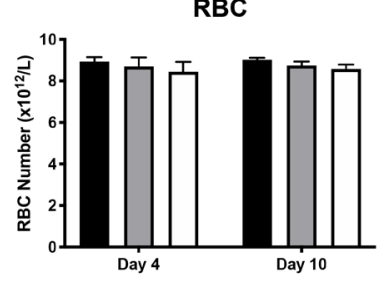

Splenocytes

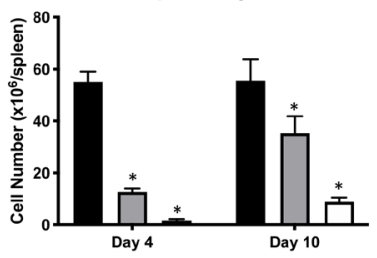

RBC

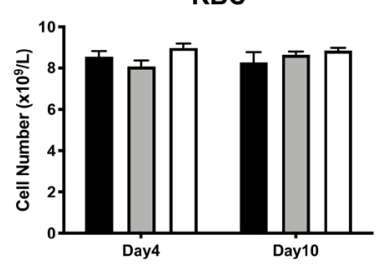

Splenocytes

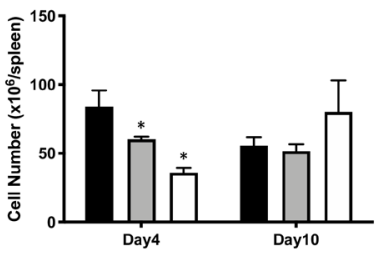

Platelets

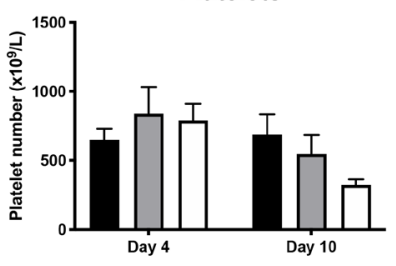

untreated

$\square 740 \mathrm{kBq}$

$\square 1480 \mathrm{kBq}$
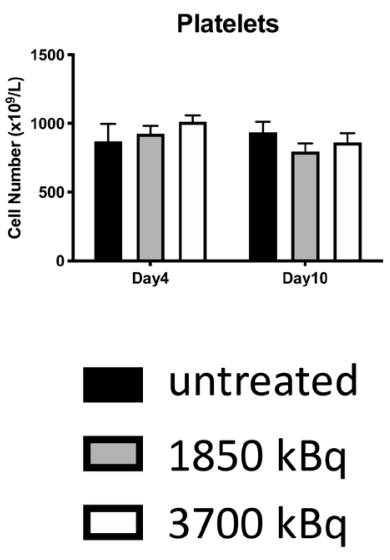

Figure 6: ${ }^{177} \mathrm{Lu}-30 \mathrm{~F} 11$ or ${ }^{131} \mathrm{I}-30 \mathrm{~F} 11$ antibody transiently depleted CD45+ immune cell subsets without affecting platelets, red blood cells, or bone marrow cells. Treatment of non-tumor bearing $\mathrm{C} 57 \mathrm{~B} / 6$ mice with $(\mathbf{A}) 0.74$ or $1.48 \mathrm{MBq}{ }^{177} \mathrm{Lu}-$ 30F11; (B) 1.85 or $3.7 \mathrm{MBq}{ }^{131} \mathrm{I}-30 \mathrm{~F} 11$ antibody was similarly effective in transiently lymphodepleting various immune cell populations without affecting bone marrow cells, red blood cells, and platelets. Asterisks signify $P$ values $<0.05$. 
OVA lymphoma tumor cells. Seven days post-tumor cell injection, when tumor volume reached $\sim 100 \mathrm{~mm}^{3}$, two groups of mice were treated with $3.7 \mathrm{MBq}{ }^{131} \mathrm{I}-30 \mathrm{~F} 11$ (20 $\mu \mathrm{g})$, while the third group was left untreated. Four days post-lymphodepletion, OVA-specific CD8+ T cells were purified using anti-CD8 magnetic beads from CD45.2 OT I mice according to the manufacturer's protocol (Miltenyi Biotec, Auburn, CA). One group of mice treated with 3.7 MBq ${ }^{131} \mathrm{I}-30 \mathrm{~F} 11$ was given a single $\mathrm{i}$. $\mathrm{v}$. injection of $10^{6}$ CD45.2 OT I CD8+ cells. Tumor volume and body weight were monitored, and mice were sacrificed when tumor volume exceeded $4,000 \mathrm{~mm}^{3}$ or tumors became necrotic. Blood and spleen were assessed for immune cell subsets and presence of engrafted CD45.2 OT I cells by flow cytometry.

\section{Comparative lymphodepletion studies with ${ }^{131}$ I-30F11 and ${ }^{177} \mathrm{Lu}-30 \mathrm{~F} 11$}

Female adolescent $\mathrm{C} 57 \mathrm{Bl} / 6$ mice were injected i.p. with $20 \mu \mathrm{g}$ 30F11 labelled with 0.74 or $1.48 \mathrm{MBq}$ of ${ }^{177} \mathrm{Lu}$ or with 1.85 or $3.7 \mathrm{MBq}$ of ${ }^{131}$ I to determine the ability to selectively deplete immune cell subsets. Immune cell subset quantitation was performed by flow cytometry as described above.

\section{Comparative lymphodepletion and tumor control studies with ${ }^{131} \mathrm{I}-30 \mathrm{~F} 11$ and ${ }^{177} \mathrm{Lu}-30 \mathrm{~F} 11$ in OT I mouse model}

Female 5 weeks old C57B1/6 CD45.1 mice were injected subcutaneously with OVA expressing CD45+ E. G7-OVA lymphoma tumor cells until $100 \mathrm{~mm}^{3}$ tumor volume was reached. Seven days post-tumor cell injection, mice were treated with ${ }^{177} \mathrm{Lu}-30 \mathrm{~F} 11$ (1.48 MBq), ${ }^{131} \mathrm{I}-30 \mathrm{~F} 11$ (3.7 $\mathrm{MBq}$ ), or received no lymphodepletion treatment. Four days post-lymphodepletion, OVA-reactive CD8+ T cells isolated from CD45.2 OT I mice were administered to tumor-bearing mice. The tumor volume, body weight, immune cell subsets and presence of engrafted cells were monitored as above.

\section{Statistical analysis}

Power analysis for the in vivo studies was estimated using PASS version 11 (NCSS, Inc.) using simulations of

A

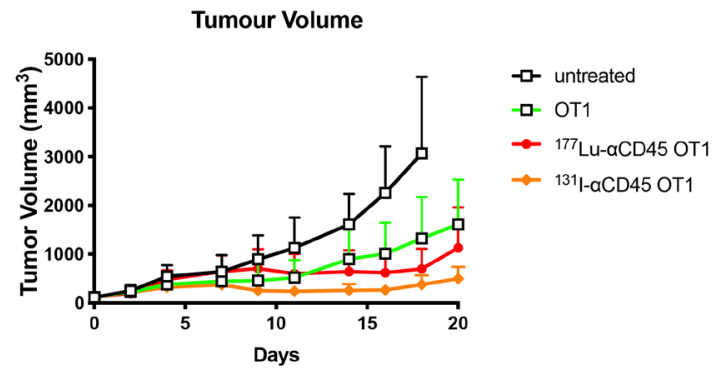

B
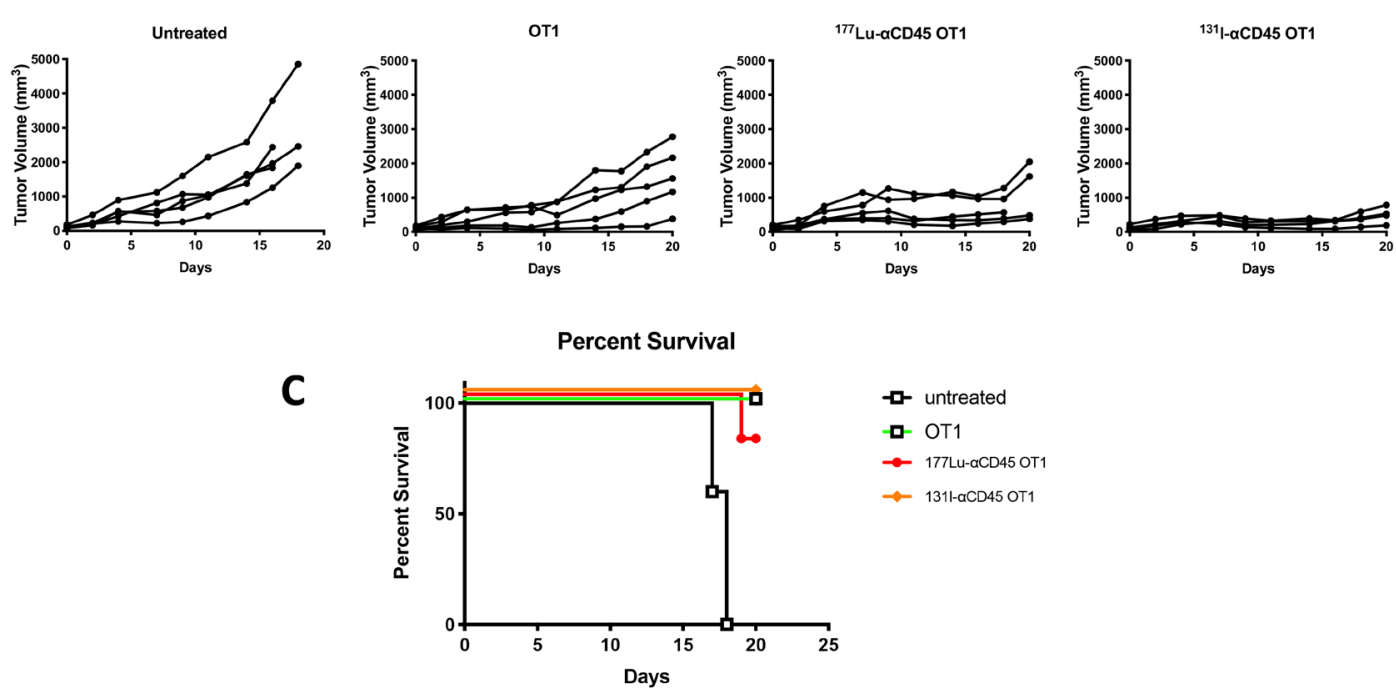

Figure 7: Comparative tumor control by ${ }^{177}$ Lu-30F11 or ${ }^{131} \mathrm{I}-30 \mathrm{~F} 11$ antibody. Following E. G7 tumor engraftment, mice either received no treatment or were conditioned with $1.48 \mathrm{MBq}{ }^{177} \mathrm{Lu}-30 \mathrm{~F} 11$ or $3.7 \mathrm{MBq}{ }^{131} \mathrm{I}-30 \mathrm{~F} 11$ on Day 0 and then received $10^{6}$ OT I CD8+ CD45.2 OVA reactive T cells on day 4. (A) ${ }^{177} \mathrm{Lu}-30 \mathrm{~F} 11$ and $131 \mathrm{I}-\mathrm{CD} 45$-mediated targeted conditioning prior to adoptively transferred OT I T cells enabled control of E.G7 tumor growth. (B) Tumor size for individual mice in each group is displayed. OT I T cell persistence and expansion was confirmed in mice at the time of sacrifice. (C) Survival of mice in treated and in untreated control groups. 
different cells depletions/tumor volumes based on pilot or literature data and conservative assumptions regarding the groups treated with the radiolabeled antibodies. All simulations showed power of at least $83 \%$ with only five animals per group because of the large differences between treated and untreated animals. Thus, 5 mice per group were utilized in the in vivo studies. GraphPad Prism 7 was used to analyze all the data (GraphPad Software, Inc., La Jolla, CA, USA). Differences among the groups were assessed using Student $t$-tests and oneway ANOVAs for multiple comparisons. Differences were considered significant at $p<0.05$.

\section{Abbreviations}

CAR: chimeric antigen receptor; ACT: adoptive cell therapy; Tregs: regulatory T cells; MDSCs: myeloid derived suppressor cells; TAMs: tumor-associated macrophages; CRS: cytokine release syndrome; ICANS: immune effector cell-associated neurotoxicity syndrome; RIT: radioimmunotherapy; Ab: antibody; i.p.: intraperitoneally; OVA: ovalbumin; CPM: counts per minute.

\section{Author contributions}

ED, EMG, MSB, and DLL came up with the idea and design of the study; ED supervised the research; WD, KJHA and $\mathrm{RG}$ performed the experiments and collected the data; WD, ED and DLL analysed the data; ED, WD, EMG and DLL wrote the manuscript; all authors approved the manuscript.

\section{ACKNOWLEDGMENTS}

The authors would like to thank Mrs. Mackenzie Malo and Dr. Rubin Jiao for technical assistance.

\section{CONFLICTS OF INTEREST}

The research was funded by Actinium Pharmaceuticals and the funder had input into designing of the study and writing the manuscript. ED received the funding from Actinium Pharmaceuticals. DL and EG are employees of Actinium Pharmaceuticals. The rest of the authors declare no conflicts of interest.

\section{FUNDING}

This study was supported by research funding from Actinium Pharmaceutical Inc. and Fedoruk Center for Nuclear Innovation.

\section{REFERENCES}

1. Makita S, Yoshimura K, Tobinai K. Clinical Development of anti-CD19 Chimeric Antigen Receptor T-cell Therapy for B-cell non-Hodgkin Lymphoma. Cancer Sci. 2017; 108:1109-1118. https://doi.org/10.1111/cas.13239. [PubMed]

2. Jacobson CA. CD19 Chimeric Antigen Receptor Therapy for Refractory Aggressive B-Cell Lymphoma. J Clin Oncol. 2019; 37:328-335. https://doi.org/10.1200/JCO.18.01457. [PubMed]

3. Zhang J, Wang L. The Emerging World of TCR-T Cell Trials Against Cancer: A Systematic Review. Technol Cancer Res Treat. 2019; 18:1533033819831068. https:// doi.org/10.1177/1533033819831068. [PubMed]

4. Gattinoni L, Finkelstein SE, Klebanoff CA, Antony PA, Palmer DC, Spiess PJ, Hwang LN, Yu Z, Wrzesinski C, Heimann DM, Surh CD, Rosenberg SA, Restifo NP. Removal of homeostatic cytokine sinks by lymphodepletion enhances the efficacy of adoptively transferred tumorspecific CD8+ T cells. Version 2. J Exp Med. 2005; 202:907912. https://doi.org/10.1084/jem.20050732. [PubMed]

5. Yao X, Ahmadzadeh M, Lu YC, Liewehr DJ, Dudley ME, Liu F, Schrump DS, Steinberg SM, Rosenberg SA, Robbins PF. Levels of peripheral CD4(+)FoxP3(+) regulatory T cells are negatively associated with clinical response to adoptive immunotherapy of human cancer. Blood. 2012; 119: 5688-5696. https://doi.org/10.1182/blood-2011-10-386482. [PubMed]

6. Rosenberg SA, Restifo NP. Adoptive cell transfer as personalized immunotherapy for human cancer. Science. 2015; 348:62-68. https://doi.org/10.1126/science.aaa4967. [PubMed]

7. Porta C, Sica A, Riboldi E. Tumor-associated myeloid cells: new understandings on their metabolic regulation and their influence in cancer immunotherapy. FEBS J. 2018; 285:717-733. https://doi.org/10.1111/febs.14288. [PubMed]

8. Norelli M, Camisa B, Barbiera G, Falcone L, Purevdorj A, Genua M, Sanvito F, Ponzoni M, Doglioni C, Cristofori P, Traversari C, Bordignon C, Ciceri F, et al. Monocytederived IL-1 and IL-6 are differentially required for cytokine-release syndrome and neurotoxicity due to CAR T cells. Nat Med. 2018; 24:739-748. https://doi.org/10.1038/ s41591-018-0036-4. [PubMed]

9. Giavridis T, van der Stegen SJC, Eyquem J, Hamieh M, Piersigilli A, Sadelain M. CAR T cell-induced cytokine release syndrome is mediated by macrophages and abated by IL-1 blockade. Nat Med. 2018; 24:731-738. https://doi. org/10.1038/s41591-018-0041-7. [PubMed]

10. Hay KA, Hanafi LA, Li D, Gust J, Liles WC, Wurfel MM, López JA, Chen J, Chung D, Harju-Baker S, Cherian S, Chen X, Riddell SR, et al. Kinetics and biomarkers of severe cytokine release syndrome after CD19 chimeric antigen receptor-modified T-cell therapy. Blood. 2017; 130:22952306. https://doi.org/10.1182/blood-2017-06-793141. [PubMed]

11. Syrjälä M, Ruutu T, Jansson SE. A Flow Cytometric Assay of CD34-Positive Cell Populations in the Bone Marrow. Br J Haematol. 1994; 88:679-684. https://doi. org/10.1111/j.1365-2141.1994.tb05104.x. [ [PubMed] 
12. Nath R, Geoghegan EM, Ulrickson ML, Spross JA, Lichtenstein RH, Konerth S, Fisher DR, Liang Q, Ludwig D, Reddy V, Berger MS, Gyurkocza B. Sierra Clinical Trial Dosimetry Results Support Low Dose Anti-CD45 Iodine (131I) Apamistamab [Iomab-B] for Targeted Lymphodepletion Prior to Adoptive Cell Therapy. Blood. 2019; 134:1958. https://doi.org/10.1182/ blood-2019-128838.

13. Bushnell DL, Bodeker KL. Overview and Current Status of Peptide Receptor Radionuclide Therapy. Surg Oncol Clin N Am. 2020; 29:317-326. [PubMed]

14. Bögemann M, Herrmann K, Radtke JP, Rahbar K. [PSMA radioligand therapy in patients with advanced prostate cancer]. [Article in German]. Urologe A. 2020; 59:680-686. https://doi.org/10.1007/s00120-020-01205-w. [PubMed]

15. Gabriel M, Nilica B, Kaiser B, Virgolini IJ. Twelve-Year Follow-up After Peptide Receptor Radionuclide Therapy. J Nucl Med. 2019; 60:524-529. https://doi.org/10.2967/ jnumed.118.215376. [PubMed]
16. Garg R, Mills K, Allen KJH, Causey P, Perron RW, Gendron D, Sanche S, Berman JW, Gorny MK, Dadachova E. Comparison of various radioactive payloads for a human monoclonal antibody to glycoprotein 41 for elimination of HIV-infected cells. Nucl Med Biol. 2020; 82-83:8088. $\quad$ https://doi.org/10.1016/j.nucmedbio.2020.02.009. [PubMed]

17. Dawicki W, Allen KJH, Jiao R, Malo ME, Helal M, Berger MS, Ludwig DL, Dadachova E. Daratumumab225Actinium conjugate demonstrates greatly enhanced antitumor activity against experimental multiple myeloma tumors. OncoImmunology. 2019; 8:1607673. https://doi.or g/10.1080/2162402X.2019.1607673. [PubMed] 